Research Paper

\title{
Vapocoolant Spray vs Lidocaine/Prilocaine Cream for Reducing the Pain of Venipuncture in Hemodialysis Patients: A Randomized, Placebo-Controlled, Crossover Study
}

 \\ 1. Department Internal Medicine, Division of Nephrology, Faculty of Medicine, Selcuk University, Konya, Turkey. \\ 2. Department of Radiology, Faculty of Medicine, Selcuk University, Konya, Turkey. \\ 3. Department Internal Medicine, Division of Nephrology, Kütahya State Hospital, Kütahya, Turkey \\ 4. Ministry of Health, Konya, Turkey. \\ 5. Department of Anesthesia and Intensive Care, Faculty of Medicine, Selcuk University, Konya, Turkey.
}

Corresponding author: Gülperi Çelik; MD, Department Internal Medicine, Division of Nephrology, Faculty of Medicine, Selcuk University, Konya, Turkey. Tel: 903322415000; Fax: 903322416065; gulpericelik@gmail.com

() Ivyspring International Publisher. This is an open-access article distributed under the terms of the Creative Commons License (http://creativecommons.org/ licenses/by-nc-nd/3.0/). Reproduction is permitted for personal, noncommercial use, provided that the article is in whole, unmodified, and properly cited.

Received: 2011.06.03; Accepted: 2011.07.27; Published: 2011.10.12

\begin{abstract}
Objective: Patients undergoing hemodialysis are repeatedly exposed to stress and pain from approximately 300 punctures per year to their arteriovenous fistula. This study was designed to measure pain associated with venepuncture during AVF cannulation and to compare the effectiveness of ethyl chloride vapocoolant spray, topical eutectic mixture of local anesthetics (EMLA) cream and placebo in controlling pain caused by venepuncture of arteriovenous fistula patients undergoing chronic hemodialysis.

Methods: This randomized, placebo-controlled, crossover study, included $4 \mathrm{I}$ patients undergoing conventional hemodialysis three times a week. First intervention was conducted as baseline pain assessment (control). In the three consecutive dialysis sessions, every patient randomly received I) ethyl chloride vapocoolant spray, 2) EMLA, or 3) placebo cream before venepuncture. Pain perception was recorded by patients immediately after cannulation on a 0-100 mm visual analogue scale (VAS). $\mathrm{p}<0.05$ was considered as significant.

Results: VAS scores presented a marked inter-individual variation during venepuncture. EMLA application resulted in significantly lower total pain scores compared to control and all other interventions $(p<0.05)$. No patient experienced severe pain with EMLA or vapocoolant. The patients reported less moderate and severe pain with EMLA, and vapocoolant spray compared to control and placebo interventions. Moderate and severe pain scores were similar between EMLA and vapocoolant spray $(p>0.05)$.

Conclusion: Venipuncture for AVF cannulation causes mild to moderate pain in hemodialysis patients. Although local application of EMLA is more effective than in preventing venepuncture pain, ethyl chloride vapocoolant is as effective as EMLA for preventing mild to moderate puncture pain in patients undergoing hemodialysis.
\end{abstract}

Key words: Hemodialysis, arteriovenous fistula, venepuncture pain, vapocoolant spray, visual analogue scale

\section{Introduction}

Chronic renal failure is a devastating medical, social, and economic problem for both patients and their families. Hemodialysis is the most frequently used renal replacement therapy with the arteriove- 
nous fistula (AVF) being the gold standard for vascular access in hemodialysis patients (1). The extracorporeal blood flow rate is achieved through venous puncture, most often via two needles, one for blood aspiration called the arterial needle, one for venous reinjection called the venous needle $(2,3)$.

Patients with end-stage renal disease undergoing hemodialysis are repeatedly exposed to stress and pain from approximately 300 punctures per year to their AVF. Considerable patient discomfort and stress can be associated with the insertion of large-gauge needles into an AVF. Alleviation of this pain might improve their acceptance of the procedure and thus, their quality of life $(1,4,5)$.

Previous research has shown that topical local anesthetic creams are effective in reducing venous puncture pain during AVF cannulation $(6,7)$. The eutectic mixture of local anesthetics, EMLA was formulated to penetrate intact skin. EMLA significantly reduces puncture pain and represents an acceptable alternate method for topical anesthesia in venous cannulation (8). Immediate topical analgesia is provided based on the chilling effect of evaporation, which is attained by spraying the determined surface with volatile liquid sprays (e.g. ethyl chloride, fluorohydrocarbon) $(6,9)$. Rapid evaporation of the volatile liquid spray from the skin surface causes a decrease in temperature and results in temporary interruption of pain sensation, possibly through desensitization of pain receptors or activation of ion channels involved in pain transmission. Page et al. (10) have demonstrated that topical vapocoolant sprays such as ethyl chloride are effective in reducing the pain during emergent venous punctures. There are no studies assessing the efficacy vapocoolant sprays in hemodialysis patients. Our hypothesis is that vapocoolant spray would be more efficacious than EMLA cream.

The primary aim of this study was to assess the effectiveness of ethyl chloride vapocoolant spray, topical EMLA cream and placebo in controlling pain caused by venepuncture of arteriovenous fistula patients undergoing chronic hemodialysis. The secondary aim was undertaken to measure pain associated with venepuncture during AVF cannulation.

\section{Methods}

This randomized, placebo-controlled, crossover study received approval from the Selcuk University Local Research Ethics Committee and all subjects gave written informed consent before participation. The study included 41 patients undergoing conventional hemodialysis three times a week. Eligible patients were adults $18 \mathrm{yr}$ of age or older of any gender who did not meet any of the following exclusion criteria: known allergies or sensitivities to lidocaine, prilocaine, or other local anesthetic; damaged, denuded, or broken skin at the designated site; concomitant use of an analgesic within the previous $24 \mathrm{~h}$; or previous use of lidocaine/ prilocaine cream.

Before the first intervention, the patients were informed about the study drugs and on how to use the visual analogue scale (VAS) for pain assessment. First intervention was conducted as baseline pain assessment (control); venepuncture was performed without any intervention and pain score was assessed. In the three consecutive dialysis sessions, every patient randomly received one of the following intervention only once before venepuncture: 1) ethyl chloride vapocoolant spray (IGS aerosols GMBH, Germany), 2) Eutectic mixture of $2.5 \%$ lidocaine and $2.5 \%$ prilocaine in an oil/water emulsion (EMLA cream ${ }^{\circledR}$ $\% 5$, Astra Zeneca, Istanbul, Turkey), or 3) placebo cream (Ultrabase cream; Schering Alman, Istanbul, Turkey).

The vapocoolant spray was sprayed from a pressure pack, at a distance of $\sim 10 \mathrm{~cm}$ for $2 \mathrm{~s}$. Liquid on the skin was allowed to evaporate for $10 \mathrm{~s}$ and the venepuncture was performed $20 \mathrm{~s}$ later after disinfection of the skin. Two ml of EMLA or placebo cream was applied to the two puncture sites under an occlusion dressing according to the product's instructions for use, 45-60 minutes before the insertion of the fistula needle. The cream was removed and the skin was disinfected before venepuncture. Venepunctures were performed with two 18G cannulas on the AV fistula. The same staff members performed the venepunctures.

Degree of pain was expressed as a pain score. Pain perception was recorded by patients immediately after cannulation on a VAS, consisting of a non-graduated $100 \mathrm{~mm}$ horizontal line ranging from “ $0=$ did not hurt at all" to " $100=$ as painful as it could be". VAS scores over 30 were considered as moderate pain and over $54 \mathrm{~mm}$ were considered as severe pain (11).

Safety and tolerability were evaluated based on the frequency of adverse events. The puncture site was inspected before and $2 \mathrm{~h}$ after cannulation for redness, pallor, swelling, damage due to cold and thrombophlebitis and local skin reactions were recorded. The relation between pain scores and fistula age, gender, smoking habits, diabetes and hepatitis $C$ virus (HCV) seropositivity were assessed.

Descriptive statistics used in the study were frequencies, percentage, mean, range, and standard deviation. The primary method of analysis involved using Chi square test whereby pair-wise comparisons were performed between the Vapocoolant group and 
the other study groups. Further, to corroborate results, pair-wise comparisons between median VAS scores were also tested with the Mann-Whitney $U$. Finally, participants' global judgment of the effectiveness of the allocated treatment was compared with Chi square tests. $\mathrm{p}<0.05$ was considered as significant.

\section{Results}

Baseline demographic and clinical variables and primary nephropathies of the 41 maintenance hemodialysis patients are presented in Table 1 . Venepuncture pain scores, assessed by VAS are presented in Table 2. VAS scores presented a marked inter-individual variation during venepuncture, with a remarkable range from $0 \mathrm{~mm}$ to $77 \mathrm{~mm}$ and $0 \mathrm{~mm}$ to $53 \mathrm{~mm}$ in the Control/placebo and treatment groups respectively. EMLA application resulted in significantly lower total pain scores compared to control and all other interventions. No patient experienced severe pain with EMLA or vapocoolant spray. The patient reported less moderate and severe pain with EMLA, and vapocoolant spray compared to control and placebo interventions. Moderate pain scores were similar between EMLA and vapocoolant spray.

No relationship was found between VAS scores and fistula age, gender, smoking or diabetes. In HCV positive patients, VAS scores of control, and placebo cream were significantly lower than HCV negative patients (18.6 \pm 20.4 vs. $31.2 \pm 16.6$ and $20.4 \pm 20.1$ vs. $36.6 \pm 18.3$ respectively) $(p<0.05)$.

All analgesic interventions were well tolerated. Only, one patient who used EMLA had a transient skin rash.

\section{Discussion}

Results of this prospective study show that compared to vapocoolant spray and placebo topical EMLA application 45 to $60 \mathrm{~min}$ prior to the venepuncture site is more effective in preventing venepuncture pain. Vapocoolant spray is as effective as EMLA for preventing mild to moderate puncture pain.

Table I. Demographic and clinical data of the $4 \mathrm{I}$ maintenance hemodialysis patients

\begin{tabular}{ll}
\hline Age (Yr) & $57.0 \pm 13.3(32-82)$ \\
Gender (males / females) & $51.2 \% / 48.8 \%$ \\
Smoking & $7(17.1 \%)$ \\
Diabetes & $10(24.4 \%)$ \\
Dialysis durations (months) & $70.5 \pm 57.4(4-216)$ \\
Age of fistula (months) & $48.1 \pm 39.8(3-180)$ \\
Radiocephalic fistula/ brachiocephalic fistula & $53.7 \% / 46.3 \%$ \\
Fistula site: Right arm/ left arm & $48.8 \% / 51.2 \%$ \\
Nephropathy ethiology & $17(41.5 \%)$ \\
Unknown & $10(24.4 \%)$ \\
Diabetic nephropathy & $6(14.6 \%)$ \\
Hypertension & $4(9.8 \%)$ \\
Glomerulonephritis & $3(7,3 \%)$ \\
Amyloidosis & $1(2.4 \%)$ \\
Lupus nephritis & \\
\hline
\end{tabular}

Data are presented as mean \pm SD (range), percentage or number of patients (percentage)

Table 2. Venipuncture pain scores, assessed by the visual analogue scale (VAS).

\begin{tabular}{|c|c|c|c|c|}
\hline & Control & Placebo & EMLA & Vapocoolant \\
\hline VAS & $28.8 \pm 17.9(0-75)$ & $33.4 \pm 19.5(0-77)$ & $10.7 \pm 10.6(0-44)^{*} \# \S$ & $14.0 \pm 12.4(0-53) \# \S$ \\
\hline $\begin{array}{l}\text { Moderate pain } \\
\text { VAS> } 30 \mathrm{~mm}\end{array}$ & $20(48.8 \%)$ & $23(56.1 \%)$ & $4(9.8 \%) \# \S$ & $4(9.8 \%) \# \S$ \\
\hline $\begin{array}{l}\text { Severe pain } \\
\text { VAS> } 54 \mathrm{~mm}\end{array}$ & $5(12.2 \%)$ & $8(19.5 \%)$ & $0(0 \%) \# \S$ & $0(0 \%) \# \S$ \\
\hline
\end{tabular}

VAS: $0 \mathrm{~mm}-100 \mathrm{~mm}$. Data are presented as Mean \pm SD (range) or number of patients (percentage). * $\mathrm{p}=0.00$ compared to vapocoolant, \# $\mathrm{p}=0.00$ compared to control, $\S \mathrm{p}=0.00$ compared to placebo. 
Venepuncture is one of the most frequently performed medical procedures. Many patients on hemodialysis repetitively experience pain and anxiety related to fistula punctures $(12,13)$. Repeated AVF punctures lead to a considerable degree of pain, due to the caliber and length of the bevel of fistula needles $(6,14)$. Our results show a wide range of variability in control and placebo pain scores. This is probably due to the differences in pain perception by individuals. Despite the fact that some patients do not experience any pain, the significant differences between the treatment and non-treatment scores in terms of severe and moderate pain displays the need for analgesia in patients undergoing venepuncture for AVF cannulation.

Human skin is protected by a corneous layer and is, therefore hardly penetrable to local anesthetics. McPhail et al (13) have found EMLA to be an effective topical anesthetic in preventing pain and alleviating anxiety associated with needling. In the study of Watson et al (9), EMLA was highly effective compared to placebo and lidocaine injection on visual analogue and verbal rating scales for relieving pain during venepuncture. Although highly effective there are some disadvantages for clinical EMLA use. Because the intact skin presents a significant barrier to available topical anesthetic preparations, to be effective EMLA requires application times of at least 45 to $60 \mathrm{~min}$ before the painful procedure (15). Our study did not assess the time or cost effectiveness between the two proposed procedures but it is obvious that in terms of time vapocoolant spray is more practical for both the patient and the staff.

Cutaneous side effects of EMLA associated with its application have rarely been reported. In this study, both ethyl chloride and EMLA were well tolerated and there was nothing to distinguish between treatments regarding adverse events. In our patient group, only one patient had allergic eruption over his brachial arteriovenous fistula due to application of EMLA. The lesions resolved after topical treatment with corticosteroids. In the study of Pérez-Pérez et al, one patient on hemodialysis developed an itchy eruption over his brachial arteriovenous fistula, where EMLA was applied three times per week, prior to puncture for hemodialysis (16). Repeated exposure to EMLA might result with more skin rash. Lidocaine and prilocaine was considered as the primary allergen $(16,17)$. Delayed sensitization was observed in $37 \%$ of patients with positive skin tests and $13.1 \%$ of patients which had previously used lidocaine-prilocaine cream (16).

Vapocoolant spray is claimed to provide good patient satisfaction and staff convenience (8). Previous studies showed ethyl chloride to be effective in cannulation pain $(18,19)$. In the study of Page et al, vapocoolant was associated with greater cannulation success, less time to administer, and more staff convenience. Unexpected events were rare and minor (mild pruritus \%4.4, mild pain \%1.1, transient erythema at the cannulation site). Some studies have displayed disadvantages for vapocoolant sprays; in the study of Biro et al (8), spraying was found to have an additional negative component due to the rather painful cooling of the treated skin surface. Another disadvantage of cold spray is its short duration of analgesic action, whereas topical or local infiltration techniques persistent effect for up to $2 \mathrm{~h}$ (8). We did not encounter any of the disadvantages of the vapocoolant; we performed the venepuncture $30 \mathrm{~s}$ after spraying the puncture site. Our patients were also comfortable during vapocoolant application and did not report any pain during cooling of the skin. Vapocoolant does have advantages over emla cream application time was significantly shorter and only involved picking up and shaking the can and spraying for $2 \mathrm{~s}$. EMLA needs to be applied at least 45 minutes before the intervention, compared with 30 seconds for the Vapocoolant spray. Although we found that vapocoolant reduces total cannulation pain less than EMLA we are in the opinion that it is easier to use, has a shorter administration time which provides more staff and patient convenience.

The possible vasoconstrictive effects of vapocoolant spray may be a concern for the patency of AVF. Prior to this study we conducted a preliminary evaluation with pulsed duplex-Doppler ultrasonography on 10 voluntary healthy adults and 10 dialysis patients. All ultrasonographic examinations were performed on Aplio XU unite (Toshiba Medical Systems, Tustin, Calif) using $7.5 \mathrm{MHz}$ linear transducer. The left arm brachial artery diameter $(\mathrm{mm})$ and vascular flow volume $(\mathrm{ml} / \mathrm{min})$ of both groups were measured in neutral position. Following the vapocoolant spray application, measurements were repeated after 1, 5 and 15 minutes. There was no significant difference in vessel diameter and flow volume after vapocoolant application in healthy adults and dialysis patients.

Demographic differences may affect pain perception. In previous studies, AV fistula puncture-related pain intensity was associated with the female sex, while no relationship existed with the duration of fistula use, the educational qualification, or the age of the subjects (1). It has been reported in other literature that intensity of pain was significantly associated with female gender, older age, cigarette smoking $(20,21)$. Our results were in accordance with 
the study of Ingalls et al (22), there was no significant relationship regarding pain and age, gender, smoking history, percent of current smokers.

As a conclusion, venipuncture for AVF cannulation causes mild to moderate pain in a group of hemodialysis patients. Although local application of EMLA is more effective than in preventing venepuncture pain, ethyl chloride vapocoolant is as effective as EMLA for preventing mild to moderate puncture pain and is more convenient for clinical use.

\section{Conflict of Interest}

The authors have declared that no conflict of interest exists.

\section{References}

1. P B S, Khakha DC, Mahajan S, Gupta S, et al. Effect of cryotherapy on arteriovenous fistula puncture-related pain in hemodialysis patients. Indian J Nephrol. 2008; 18: 155-158.

2. Choy L, Collier J, Watson AR. Lignocaine-prilocaine cream or amethocaine gel for venepunture. Acta Paediatr 1999; 88: 961-964.

3. Fischbach M, Edefonti A, Schröder C, et al. Hemodialysis in children: general practical guidelines. Pediatr Nephrol. 2005; 20: 1054-1066.

4. Quinn RR, Lamping DL, Lok CE, et al. The Vascular Access Questionnaire: assessing patient-reported views of vascular access. J Vasc Access. 2008; 9: 122-128.

5. Crespo Montero R, Rivero Arellano F, Contreras Abad MD, et al. Pain degree and skin damage during arteriovenous fistula puncture. Edtna Erca J. 2004; 30: 208-212.

6. Benini F, Gobber D, Lago P, et al. Pain management of arteriovenous fistula cannulation in haemodialysis children: efficacy of EMLA anaesthetic cream. Eur J Pain. 1998; 2: 109-113.

7. Sawyer J, Febbraro S, Masud S, et al. Heated lidocaine/tetracaine patch (Synera, Rapydan) compared with lidocaine/prilocaine cream (EMLA) for topical anaesthesia before vascular access. Br J Anaesth. 2009; 102: 210-215.

8. Biro P, Meier T, Cummins AS. Comparison of topical anaesthesia methods for venous cannulation in adults. Eur J Pain. 1997; 1: 37-42.

9. Watson AR, Szymkiw P, Morgan AG. Topical anaesthesia for fistula cannulation in haemodialysis patients. Nephrol Dial Transplant. 1988; 3: 800-802.

10. Page DE, Taylor DM. Vapocoolant spray vs subcutaneous lidocaine injection for reducing the pain of intravenous cannulation: a randomized, controlled, clinical trial. Br J Anaesth. 2010; 105: 519-525.

11. Collins SL, Moore RA, McQuay HJ. The visual analogue pain intensity scale: what is moderate pain in millimetres? Pain. 1997; 72: 95-97.

12. Alhani F. The effect of programmed distraction on the pain caused by venipuncture among adolescents on hemodialysis. Pain Manag Nurs. 2010;11: 85-91.

13. McPhail S. Hemodialysis needles can be pain free: use of a topical anaesthetic cream. J CANNT. 1992; 2: 19-20.

14. Figueiredo AE, Viegas A, Monteiro M, et al. Research into pain perception with arteriovenous fistula (AVF) cannulation. J Ren Care. 2008; 34: 169-172.

15. Kitamoto Y, Kano T, Mishima M, et al. Dermal patch anesthesia: pain-free puncture of blood access in hemodialysis patients. Am J Kidney Dis. 1992; 20: 489-491.
16. Pérez-Pérez LC, Fernández-Redondo V, Ginarte-Val M, et al. Allergic contact dermatitis from EMLA cream in a hemodialyzed patient. Dermatitis. 2006;17:85-87.

17. Gaudy-Marqueste C, Jouhet C, Castelain M, et al. Contact allergies in haemodialysis patients: a prospective study of 75 patients. Allergy. 2009; 64: 222-228.

18. Selby IR, Bowles BJ. Analgesia for venous cannulation: a comparison of EMLA (5 minutes application), lignocaine, ethyl chloride, and nothing. J R Soc Med. 1995; 88: 264-267.

19. Armstrong P, Young C, McKeown D. Ethyl chloride and venepuncture pain: a comparison with intradermal lidocaine. Can J Anaesth. 1990; 37: 656-658.

20. Hooten WM, Shi Y, Gazelka HM, et al. The effects of depression and smoking on pain severity and opioid use in patients with chronic pain. Pain. 2011;152: 223-229.

21. Parruti G, Tontodonati M, Rebuzzi C, et al. Predictors of pain intensity and persistence in a prospective Italian cohort of patients with herpes zoster: relevance of smoking, trauma and antiviral therapy. BMC Med. 2010; 8:58.

22. Ingalls NK, Horton ZA, Bettendorf $\mathrm{M}$, et al. Randomized, double-blind, placebo-controlled trial using lidocaine patch $5 \%$ in traumatic rib fractures. J Am Coll Surg. 2010; 210: 205-209. 